\title{
IMPACT OF DIFFERENT ANGIOTENSIN-CONVERTING INHIBITORS ON OUTCOMES OF POST-MYOCARDIAL INFARCTION PATIENTS
}

DOI: 10.36740/WLek202003129

\author{
Marian V. Hrebenyk, Larysa Yu. Bidovanets \\ I. HORBACHEVSKY TERNOPIL NATIONAL MEDICAL UNIVERSITY, TERNOPIL, UKRAINE
}

\begin{abstract}
The aim: To compare the long-term effects of different angiotensin-converting enzyme inhibitors in post-myocardial infarction (MI) patients.

Materials and methods: Of 445 consecutive patients with myocardial infarction, 76 (17\%) patients had co-morbid conditions, as well as were found to be compliant with secondary prevention treatment and eligible for follow-up. These patients were assigned to ramipril, perindopril or zofenopril groups in complex management of post-MI period. Subsequently, the patients were followed-up prospectively for a period of up to 24 months.

Results: Patients of zofenopril group performed better in terms of post-MI biventricular remodeling and left ventricular function recovery. Also, patients receiving zofenopril showed benefits in terms of short-term and long-term mortality as compared with patients of ramipril and perindopril groups.

Conclusion: Zofenopril may have advantages over perindopril and ramipril in the complex management of post-Ml patients in terms of prevention of negative myocardial remodeling, onset of congestive heart failure and major adverse events.
\end{abstract}

KEY WORDS: myocardial infarction; angiotensin-converting enzyme inhibitors; myocardial remodeling; co-morbidities; secondary prevention

Wiad Lek. 2020;73(3):555-560

\section{INTRODUCTION}

Myocardial infarcion (MI) is one of the most dramatic manifestations of coronary artery disease characterized by high mortality rates due to fatal arrhythmias, cardiogenic shock, pulmonary edema, as well as due to congestive heart failure (CHF). A significant number of multicenter randomized clinical trials (CONSENSUS II, SAVE, AIRE, ISIS-4, GISSI-3, CCS-1, SMILE 1-4, PREAMI, TRACE) have demonstrated that angiotensin-converting inhibitors (ACEI) have proven angioprotective properties and exhibit positive effects in terms of prevention of post-infarction myocardial remodeling and development of CHF. All ACEI are characterized by similar clinical effects due to neurohumoral blockade. Overall, the effect of any ACEI is predictable and considered as a "class effect". Nevertheless, each ACEI has its specific pharmacokinetic properties which potentially may influence the clinical outcomes. In most clinical trials different ACEI have not been directly compared. While choosing an ACEI in specific clinical scenario most physicians are guided by the available scientific evidence as well as by their personal experience. Currently most of the evidence-based data on the use of ACEI in MI are derived from the studies of ramipril [1], perindopril [2] and, in the past $10-15$ years, zofenopril [3-6].

\section{THE AIM}

To compare the long-term effects of different ACEI in post-myocardial infarction patients with co-morbidities who were adherent to secondary long-term prevention.

\section{MATERIALS AND METHODS}

A total of 455 patients $(342[75,16 \%]$ - males) with ST-elevation acute $\mathrm{MI}$ aged $62,7 \pm 1,07$ years gave informed consent for participation in the study. Depending on the prescribed ACEI, the patients were divided into three groups: group 1 patients $(\mathrm{n}=232,51 \%)$ were receiving ramipril $2.5-5,0 \mathrm{mg}$ qd, group 2 patiens $(\mathrm{n}=171,38 \%)$ were prescribed perindopril $2.0-4.0 \mathrm{mg}$ qd, group 3 patients $(n=52,11 \%)$ were administered zofenopril at initial dose of $7.5 \mathrm{mg}$ bid with subsequent dose uptitration to $60 \mathrm{mg}$ qd. Differences in the number of patients between the groups is due to variations of government supply of different ACEI foe acute MI patients. The choice of an ACEI was largely influenced by ACEI availability dependent on government supply. Comorbidities were assessed with the use of Charlson Comorbidity Index and CIRS index. Adherence with treatment recommendations was of patients was assessed according to Morisky-Green questionnaire as previously described [7]. Only compliant patients were selected for the study. These patients were followed-up prospectively for a period of up to 24 months. Serial echocardiographies, laboratory evaluations (NT-proBNP) as well as adverse events analysis (recurrent myocardial infarction, cardiovascular death) were preformed during follow-up. The study was approved by the local ethics committee.

\section{RESULTS}

In our previous study [13] we have analyzed adherence to long-term treatment with ACEI. Unfortunately, only 76 (17) \% of patients with comorbidities were found to be sufficiently adherent with treatment (Morisky index $\geq 3$ ), and, therefore, 
Table I. Baseline characteristics of patients compliant with treatment recommendations

\begin{tabular}{|c|c|c|c|}
\hline \multirow{2}{*}{ Variables } & Group I, n=36 & Group 2, n=21 & Group 3, n=19 \\
\hline & n, (\%) & n, (\%) & n, (\%) \\
\hline Gender & $26(72.22)$ & $13(61.90)$ & $15(78.94)$ \\
\hline \multicolumn{4}{|c|}{ Ml subtype } \\
\hline Anterior MI & $13(36.12)$ & $10(47.62)$ & $12(63.15)$ \\
\hline Inferior MI & $12(33.33)$ & $6(28.57)$ & $5(26.32)$ \\
\hline Recurrent MI & $7(19.44)$ & $3(14.29)$ & $2(10.53)$ \\
\hline Non-Q-wave MI & $4(11.11)$ & $2(9.52)$ & \\
\hline Charlson index & $4.95 \pm 0.15$ & $5.50 \pm 0.24$ & $5.75 \pm 1.10$ \\
\hline CIRS index & $9.40 \pm 0.16$ & $10.01 \pm 0.27$ & $10.25 \pm 1.43$ \\
\hline \multicolumn{4}{|c|}{ Comorbidities } \\
\hline No comorbidities & $2(9.52)$ & $6(16.67)$ & $3(15.79)$ \\
\hline Gastropathies & $3(14.29)$ & $4(11.11)$ & $6(31.57)$ \\
\hline Smoking & $5(23.81)$ & $10(27.78)$ & $4(21.05)$ \\
\hline COPD & $5(23.81)$ & $7(19.44)$ & $4(21.05)$ \\
\hline Arterial hypertension & $16(76.19)$ & $22(61.11)$ & $13(68.42)$ \\
\hline Diabetes mellitus & $4(19.04)$ & $8(22.22)$ & $3(15.79)$ \\
\hline \multicolumn{4}{|c|}{ Arrhtythmias } \\
\hline Supaventricular extrasystoles & $12(57.14)$ & $17(47.22)$ & $8(42.10)$ \\
\hline Ventricular extrasystoles e & $6(28.57)$ & $10(27.78)$ & $4(21.05)$ \\
\hline Supraventricular tachycardia & $2(9.52)$ & $3(8.33)$ & $3(16.7)$ \\
\hline Ventricular tachycardia & - & $2(5.55)$ & - \\
\hline Atrial fibrillation & $5(23.81)$ & $5(13.88)$ & $2(10.53)$ \\
\hline Ventricular fibrillation & - & $2(6.7)$ & - \\
\hline LBBB & $1(6.3)$ & $2(18.2)$ & - \\
\hline RBBB & $2(13.3)$ & $2(18.2)$ & - \\
\hline 2nd degree AV block & - & - & $1(9.1)$ \\
\hline Complete AV block & - & - & - \\
\hline Cardiogenic shock & $2(11.8)$ & $1(9.1)$ & - \\
\hline Pulmonary oedema & - & $1(9.1)$ & - \\
\hline LV aneurysm & - & $1(9.1)$ & - \\
\hline Acute HF Killip I & - & $6(54.5)$ & - \\
\hline Acute HF Killip II & - & $3(27.3)$ & - \\
\hline $\mathrm{PCl}$ & $21(58.33)$ & $35.3(57.14)$ & $15(78.94)$ \\
\hline
\end{tabular}

No statistically significant differences between groups were found $(p>0.05)$.

$\mathrm{AV}=$ atrio-ventricular, $\mathrm{COPD}=$ chronic obstructive pulmonary disease, $\mathrm{HF}=$ heart failure, $\mathrm{LBBB}=$ left bundle branch block, $\mathrm{LV}=$ left ventricular, $\mathrm{RBBB}=$ right bundle branch block, $\mathrm{PCl}=$ percutaneous coronary intervention

they have been selected for the study. Baseline characteristics of patients who were found to be compliant with the prescribed therapies were not statistically different from those of non-compliant patients. Similar baseline characteristics were observed in all 3 study groups (Tables I, II): no significant differences were found between the morphometric and functional indexes of group 1-3 patients with optimal adherence.

Serial NT-pro BNP measurements were performed within the first 3 months of follow-up (Figure. 1). In the ramipril group (group 1) the acute period of MI was characterized by a rapid growth of NT-proBNP levels. Similar, although less marked tendency was observed in the perindopril group (group 2). Only in zofenopril group (group 3) a gradual steady decrease of NT-proBNP levels was observed since the first days after acute MI. After 3 months follow-up, NT-proBNP levels were decrease in all three goups, the decrease being statistically significant only in zofenopril group (group 3).

Different impact of ACEI on postinfarction myocardial remodelling was assessed by serial echocardiographic exams. The analysis was performed within the early and long - term 
Table II. Baseline morphological and functional characteristics of patients

\begin{tabular}{cccc}
\hline Variables & Group I, $\mathbf{n = 3 6}$ & Group 2, $\mathbf{n = 2 1}$ & Group 3, $\mathbf{n = 1 9}$ \\
\hline RV/LV ratio & $0.72 \pm 0.02$ & $0.77 \pm 0.03$ & $0.66 \pm 0.02$ \\
\hline RWT & $0.43 \pm 0.02$ & $0.51 \pm 0.02$ & $0.42 \pm 0.01$ \\
\hline LV EDDI, cm $/ \mathrm{m}^{2}$ & $2.74 \pm 0.06$ & $2.71 \pm 0.06$ & $2.72 \pm 0.07$ \\
\hline RVI, cm $/ \mathrm{m}^{2}$ & $1.24 \pm 0.04$ & $1.23 \pm 0.05$ & $1.23 \pm 0.05$ \\
\hline LVMI, g/m ${ }^{2}$ & $137.95 \pm 7.44$ & $142.12 \pm 6.36$ & $138.05 \pm 5.57$ \\
\hline FS, \% & $24.11 \pm 1.07$ & $26.17 \pm 0.79$ & $26.10 \pm 1.49$ \\
\hline LVEF, \% & $47.09 \pm 1.59$ & $48.65 \pm 1.31$ & $46.18 \pm 1.22$ \\
\hline NYHA class & $2.00 \pm 0.14$ & $2.11 \pm 0.20$ & $1.67 \pm 0.33$ \\
\hline
\end{tabular}

No statistically significant differences between groups were found $(p>0.05)$.

$F S=$ fractional shortening, LV = left ventricular, LVEF = left ventricular ejection fraction, LVMI = left ventricular mass index,

NYHA = New York Heart Association, RV = right ventricular, RVI = right ventricular index, RWT = relative wall thickness.
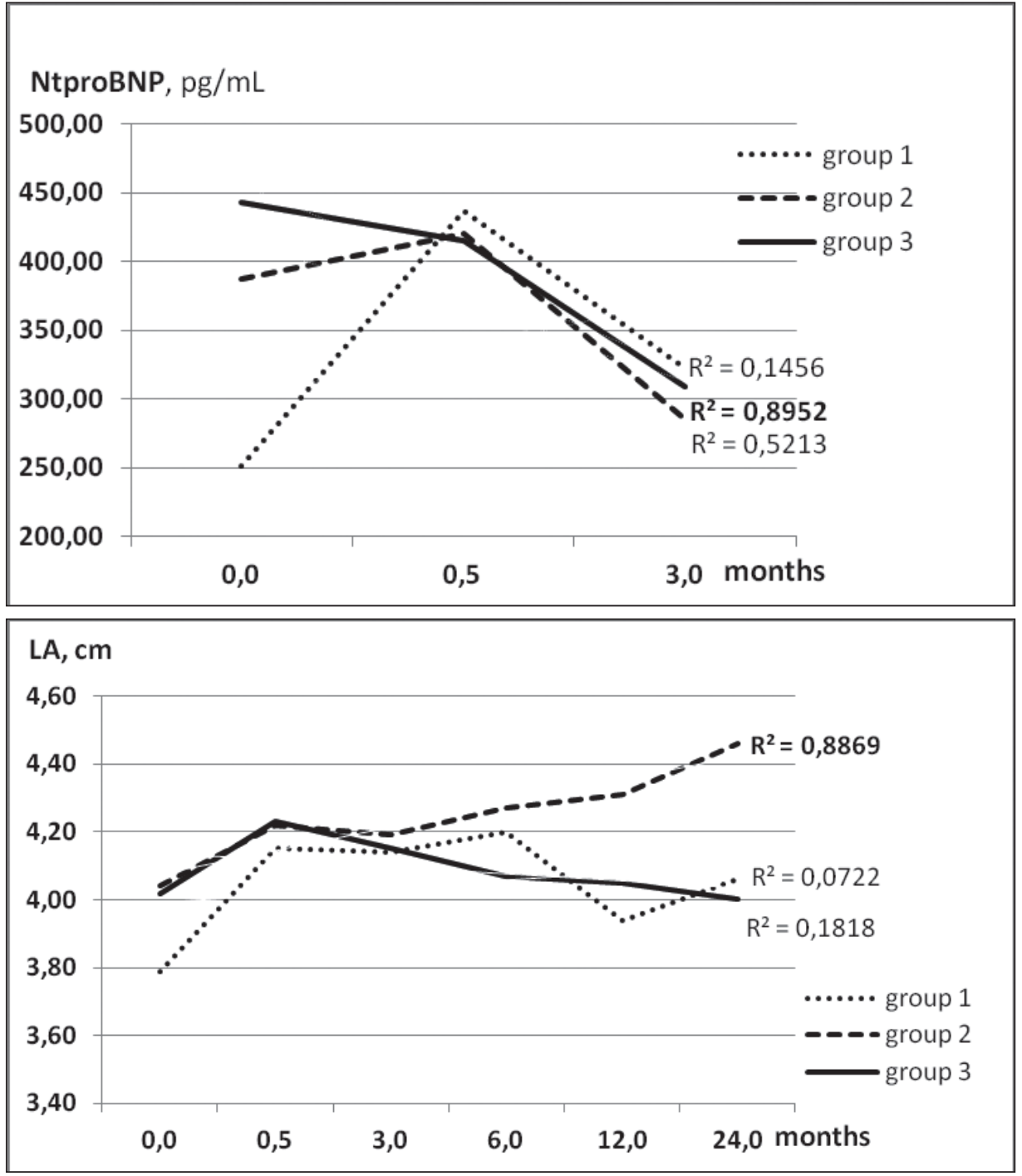

Fig. 1. Serial changes of N-terminal probrain natriuretic peptide (NT-proBNP) within the first 3 months after acute myocardial infarction.
Fig. 2. Serial changes of left atrial dimensions during follow-up. $L A=$ left atrial antero-posterior dimension. (up to 24 months) period. As compared with perindopril (group 2), the use of zofenopril was effective in terms of prevention of postinfarction LV and/or left atrial enlargement. No increase of left atrial antero-posterior dimension (Figure 2) or left atrial volume was observed in the ramipril and zofenopril group. In patients receiving perindopril (group 3), significant left atrial dilatation was observed by the end of follow-up.
Analysis of serial changes of ventricular dimensions revealed gradual increase of end-diastolic dimensions of both ventricles, especially of the right one, within 24 months follow-up in patients who were administered ramipril and perindopril. In complex therapy with the use of zofenopril the LV end-diastolic dimension index decreased significantly; similar changes were observed in the right ventricle as well. (Figure. 3, 4). 

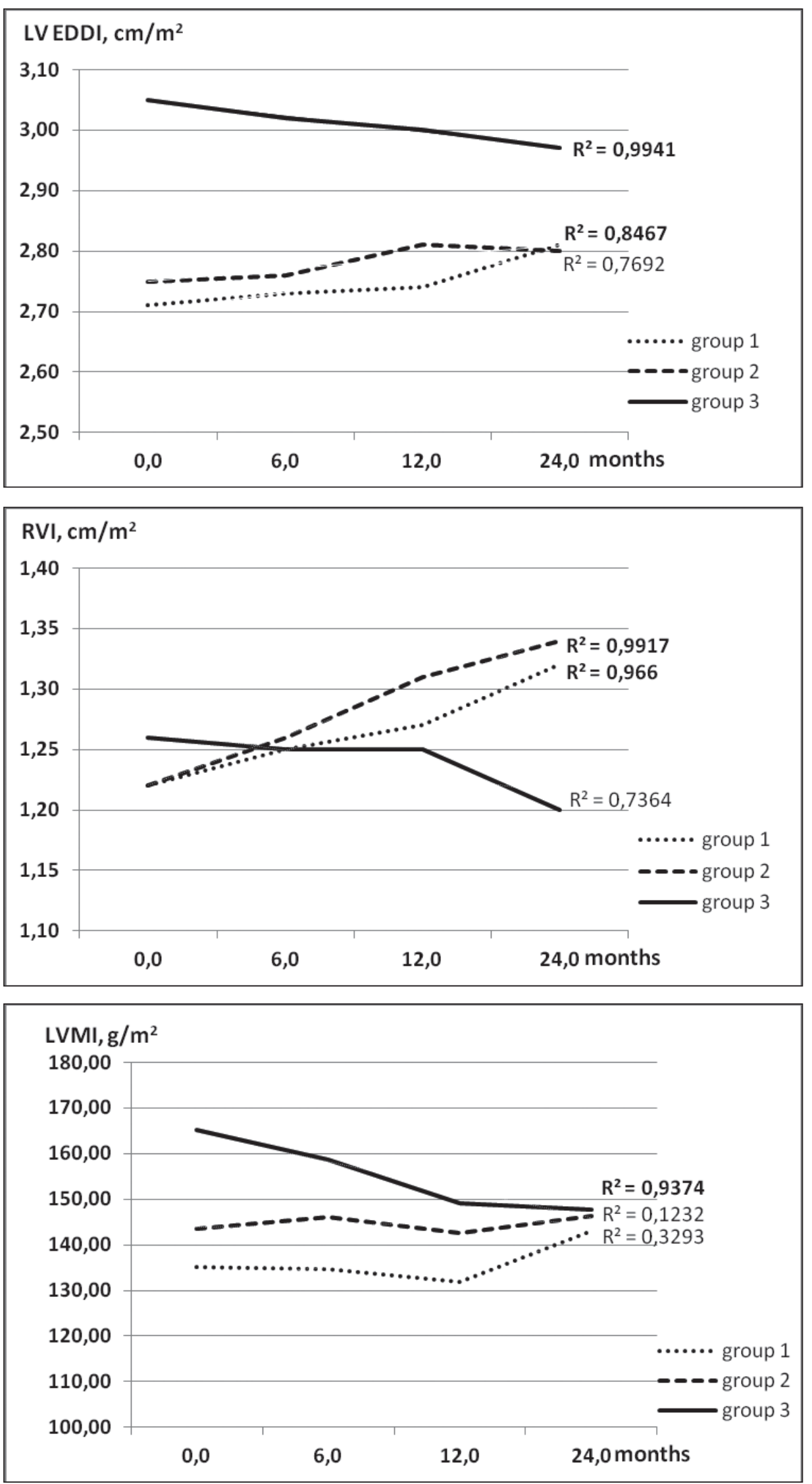

Fig. 3. Serial changes of left ventricular dimensions during follow-up. LV EDDI = left ventricular end-diastolic dimension index.

Fig. 4. Serial changes of right ventricular dimensions during follow-up. RVI = right ventricular index.
Fig. 5. Serial changes left ventricular mass index (LVMI) during follow-up.
Positive changes of mass indexes were also seen, i.e., left ventricular mass index and relative wall thickness significantly decreased (Figure. 5, 6).
Left ventricular function was improving in the ramipril and zofenopril groups (Figure. 7,8 ) as shown by serial changes of LV ejection fraction and fractional shortening. Thirty-day 

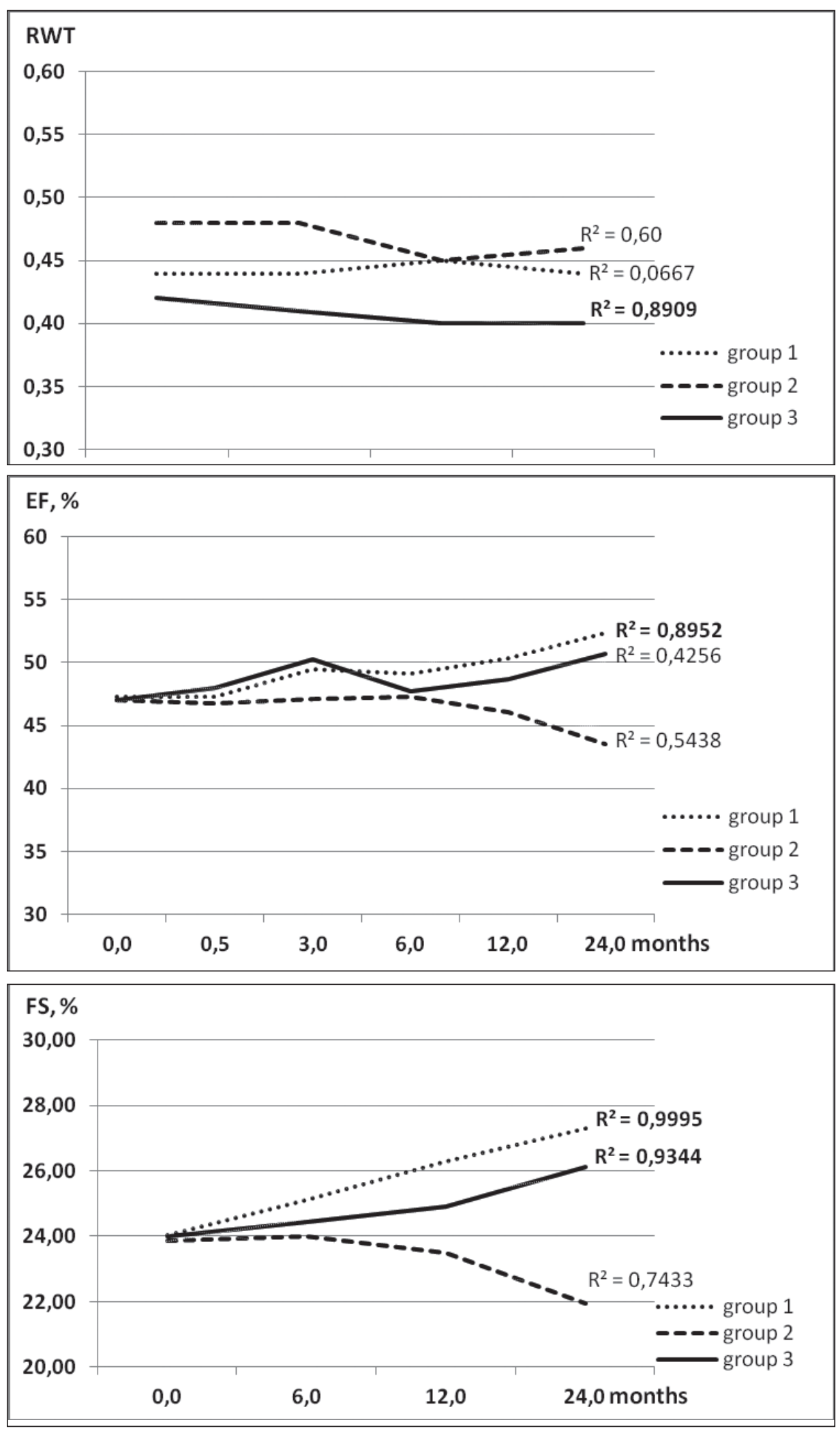

Fig. 6. Serial changes relative wall thickness (RWT) during follow-up.

Fig. 7. Serial changes left ventricular ejection fraction (EF) during follow-up.
Fig. 8. Serial changes fractional shortening (FS) during follow-up. mortality in groups 1-3 was significantly different in the ramipril and perindopril groups $(\mathrm{p}=0,003)$ as compared with zofenopril group. No 30-day mortality was registered in zofenopril group. There was no statistically significant difference between the groups in terms of causes of death. Lower survival in perindopril group (group 2) was possibly related to age factor (Table III).

\section{DISCUSSION}

As the baseline clinical, morphometric and functional characteristics of patients of all three groups who were found to be compliant with the prescribed therapy were similar, this allowed to assess the effectiveness of different ACEI in the secondary prevention of MI. 
Table III. Mortality rates

\begin{tabular}{ccccc}
\hline Variables & Group 1, $\mathbf{n = 3 6}$ & Group 2, $\mathbf{n = 2 1}$ & Group 3, $\mathbf{n = 1 9}$ & P value \\
\hline 30-day mortality,\% & 4.7 & 12.9 & 3.8 & $\begin{array}{l}\mathrm{p} 1-3=0,778 \\
\mathrm{p} 1-2=0,003 \\
\mathrm{p} 2-3=0,063\end{array}$ \\
\hline One-year mortality*, \% & 10.3 & 23.4 & 5.8 & $\begin{array}{r}\mathrm{p} 1-3=0,317 \\
\mathrm{p} 1-2=0,0004 \\
\mathrm{p} 2-3=0,005\end{array}$
\end{tabular}

*Log-rank $p$ value between the groups is 0,01

Our observations support the assumption that the effect of various ACEI on postinfarction myocardial remodeling may be different. In contrast to ramipril and perindopril which were associated with a transient increase of NT-proBNP levels, zofenopril was associated with consistent lowering of NT-pro BNP throughout the follow-up. Thus, the observed serial changes of NT-proBNP levels indicate that zofenopril, as compared with ramipril and perindopril, may be considered the preferred agent for prevention of post-MI heart failure.

Different ACEI were also associated with different tendencies in terms of postinfarction myocardial remodeling. As compared with ramipril and perindopril, zofenopril showed a more pronounced effect on prevention of post-MI LV dilatation as well as a favourable effect on LV mass indexes.

The effect on LV contractility as assessed by serial changes of LV ejection fraction and fractional shortening was favourable in all three groups. However, these findings should be interpreted with caution. While analyzing these changes in context with concomitant morphological changes (i.e., increase of ventricular dimensions in the ramipril group) one may speculate that the increase of the LV ejection fraction occurred according to Frank-Starling law, thus putting these patients at risk of further LV dilatation and development of ischemic cardiomyopathy.

Also, different survival rates illustrate the differences between the effects of the studied ACEI. The use of zofenopril was shown to be associated with better survival.

\section{CONCLUSION}

Zofenopril may have advantages in the long-term complex management of post-MI patients over perindopril and ramipril in terms of prevention of negative myocardial remodeling, onset of congestive heart failure and major adverse events.

\section{REFERENCES}

1. AIRE Study Investigators. Effect of ramipril on mortality and morbidity of survivors of acute myocardial infarction with clinical evidence of heart failure. Lancet. 1993; 342(8875):821-828.

2. Ferrari $\mathrm{R}$; Perindopril and Remodeling in Elderly with Acute Myocardial Infarction Investigators. Effects of angiotensin-converting enzyme inhibition with perindopril on left ventricular remodeling and clinical outcome: results of the randomized Perindopril and Remodeling in Elderly with Acute Myocardial Infarction (PREAMI) Study. Arch Intern Med 2006; 166(6): 659-666.

3. Ambrosioni E, Borghi C, Magnani B. The effect of the angiotensinconverting-enzyme inhibitor zofenopril on mortality and morbidity after anterior myocardial infarction. The Survival of Myocardial Infarction Long-Term Evaluation (SMILE). N Engl J Med. 1995; 332(2): 80-85.
4. Borghi C, Ambrosioni E, Survival of Myocardial Infarction Long-Term Evaluation-2 working party. Double-blind comparison between zofenopril and lisinopril in patients with acute myocardial infarction: results of the Survival of Myocardial Infarction Long-Term Evaluation-2 (SMLLE-2) study.Am Heart J2003; 145(1):80-87.

5. Borghi C, Ambrosioni E, Survival of Myocardial Infarction Long-Term Evaluation-2 working party. Effects of zofenopril on myocardial ischemia in post-myocardial infarction patients with preserved left ventricular function: the Survival of Myocardial Infarction Long-Term Evaluation (SMILE)-ISCHEMIA study. Am Heart J 2007; 153:445. e7-e14.

6. Borghi C, Omboni S, Novo S et al. Efficacy and safety of zofenopril versus ramipril in the treatment of myocardial infarction and heart failure: a review of the published and unpublished data of the randomized double-blind SMILE-4 study. Adv Ther. 2018; 35(5): 604-618.

7. Hrebenyk MV, Levchyk 0l. Prykhylnist do dovhotryvaloyi vtorynnoyi profilaktyky pislya infarktu miokarda [Adherence to long-term secondary prevention after myocardial infarction]. Bulletin of Social Hygiene and Health Protection of Ukraine 2018;1(75):18-23. (in Ukrainian).

8. Hrebenyk MV, Bidovanets LY, Levchyk OI. Kliniko-funktsionalni paraleli hostroho periodu infarktu miokarda z nastupnoyu prykhylnistyu do tryvaloyi terapii IAPF u kompleksnij vtorynnij profilaktytsi [Clinical and functional dependences of acute myocardial infarction and further compliance to the long-term angiotensin-converting inhibitors intake for secondary prevention]. Liky Ukrainy Plus 2020; 1(40) (in Ukrainian)

\section{ORCID and contributionship:}

Marian V. Hrebenyk: 0000-0002-8118-5742 A,B,C,D,E,E

Larysa Yu. Bidovanets:0000-0002-3978-2105 B,C,E,F

\section{Conflict of interest:}

The authors declare to have no conflict of interest.

\section{CORRESPONDING AUTHOR Marian V. Hrebenyk \\ TNMU, Majdan Voli, 1 \\ 46025 Ternopil, Ukraine \\ tel: +38068 8321984 \\ e-mail:marian.grebenyk@gmail.com}

Received: 17.01 .2020

Accepted: 05.03 .2020

A - Work concept and design, B - Data collection and analysis, C - Responsibility for statistical analysis,

D-Writing the article, $\mathbf{E}$-Critical review, $\mathbf{F}$ - Final approval of the article 